\title{
Thermal Expansion of Some Copper Alloys
}

\author{
By Peter Hidnert and Harrison S. Krider
}

\begin{abstract}
This paper gives the results of an investigation on the linear thermal expansion of some brasses, bronzes, and other copper alloys for various temperature ranges between room temperature and $300^{\circ} \mathrm{C}$.

The coefficients of expansion of tellurium copper $(0.6 \%$ of tellurium $)$ are in close agreement with the coefficients of expansion of electrolytic copper $(99.97 \%)$. The addition of 10 percent of aluminum, 2 percent of iron, and 0.4 percent of tellurium to copper had slight effect on the coefficients of expansion.

Figures 1 and 2 of the paper summarize the coefficients of expansion of copper-zinc alloys and copper-nickel alloys with and without addition of other elements, from the present and previous investigations. The curve for copper-zinc alloys shows that the coefficients of expansion increase with increase in the zinc content. A change in the slope of this curve due to a change from alpha brasses to beta brasses was noted. The addition of 10 to 18 percent of nickel to copper-zinc alloys reduced the coefficients of expansion to a marked extent, but the addition of tin, lead, or aluminum increased the coefficients of expansion.

The curves for copper-nickel alloys in figure 2 indicate that the coefficients of expansion decrease with increase in the nickel content. The curvilinear relation between the coefficients of expansion and nickel content (atomic percent) of copper-nickel alloys is typical of relations for properties of binary alloys having structures composed of solid solutions.
\end{abstract}

\section{Introduction}

This paper gives the results of an investigation on the linear thermal expansion of some brasses, bronzes, and copper alloys for various temperature ranges between room temperature and $300^{\circ} \mathrm{C}$. One sample of tellurium aluminum bronze was investigated to $400^{\circ} \mathrm{C}$.

\section{Materials Investigated}

The chemical compositions and the treatments of the materials investigated are given in table 1 . The samples, the values for chemical compositions, and information about the treatments were furnished by Chase Brass \& Copper Co., Waterbury, Conn.

The length of each sample used in the determinations of linear thermal expansion was $300 \mathrm{~mm}$ (11.8 in.). The cross sections of the samples were circular, with diameters of 0.20 to $0.37 \mathrm{in}$. (5 to $9 \mathrm{~mm}$ ).

\section{Apparatus}

Two types of precision micrometric thermalexpansion apparatus described by Hidnert [1], ${ }^{1}$ and Souder and Hidnert [3] were used for determining the linear thermal expansion of the samples. A stirred liquid bath was used for determinations in the range from $20^{\circ}$ to $300^{\circ} \mathrm{C}$ and an air type heating chamber for determinations in the range from $20^{\circ}$ to $400^{\circ} \mathrm{C}$.

\section{Results and Discussion}

The observations ${ }^{2}$ obtained on heating and cooling the samples to various temperatures were plotted. The expansion and contraction curves ${ }^{2}$ for all of the samples except 1718 and 1719 showed no irregularities. The expansion curves of samples 1718 and 1719 indicated an irregularity be-

\footnotetext{
${ }^{1}$ Figures in brackets indicate the literature references at the end of this paper.

${ }^{2}$ Neither the observations nor the curves are presented in this paper.
} 
TABLE 1. Coefficients of linear expansion of some copper alloys

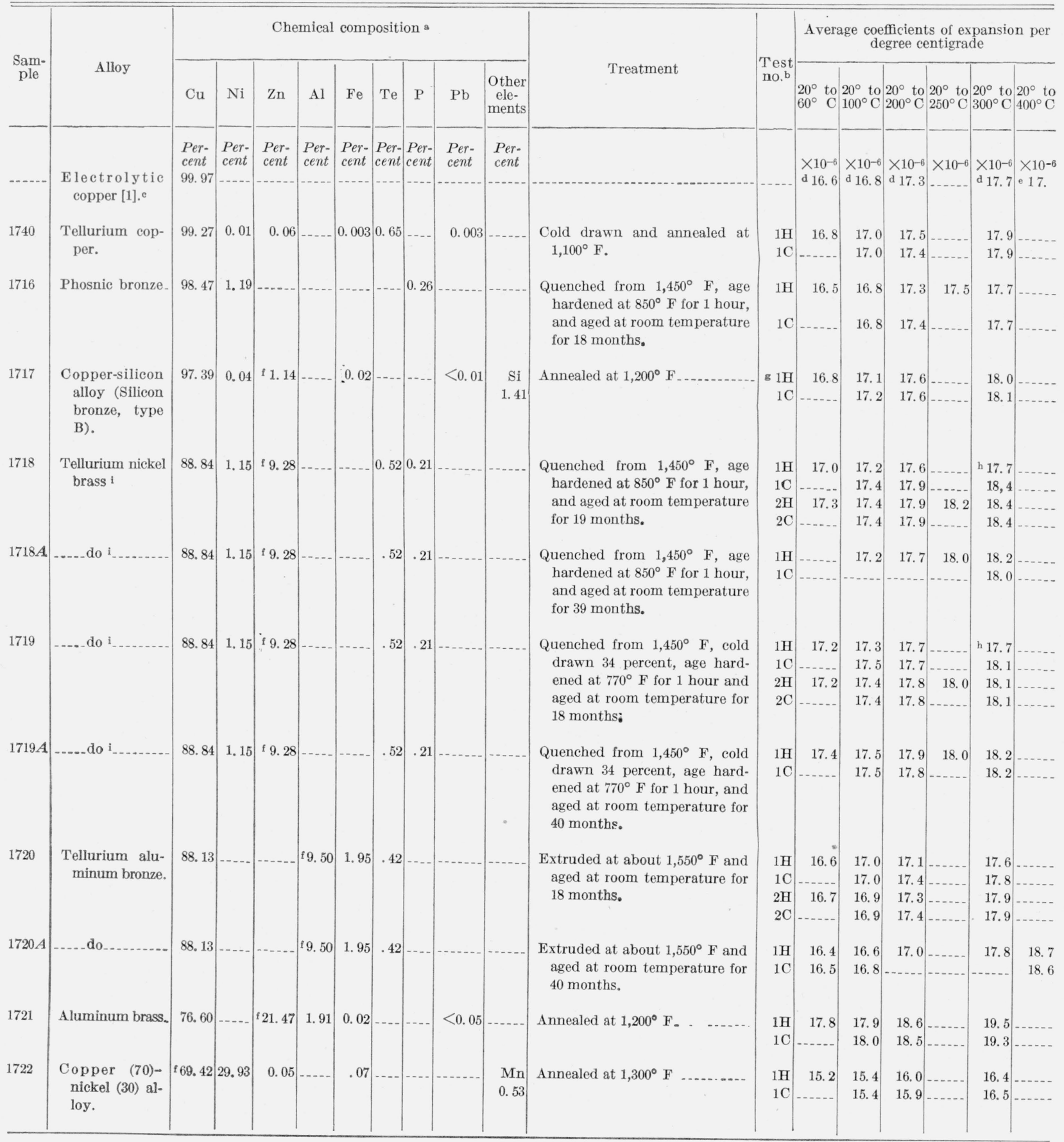

a All compositions in this paper are given in percent by weight except where indicated otherwise.

b $\mathrm{H}$ indicates heating and $\mathrm{C}$, cooling.

- Added for comparison with tellurium copper and the copper alloys in this table.

d From Hidnert [1].

- From Esser and Eusterbrock [2] for electrolytic copper annealed at $1,020^{\circ} \mathrm{C}$.

$i$ By difference.

g Before this test, sample was heated to $300^{\circ} \mathrm{C}$ and cooled to room temperature.

h Irregularity in expansion curve between $200^{\circ}$ and $300^{\circ} \mathrm{C}$.

i Formerly known as Telnic bronze. All of the zinc has been essentially omitted from Telnic bronze manufactured at the present time. 
tween $200^{\circ}$ and $300^{\circ} \mathrm{C}$ during the first heating. However, on repeated heating to $300^{\circ} \mathrm{C}$, no irregularities were observed.

Table 1 gives the coefficients of linear thermal expansion that were computed from the curves obtained on heating and on cooling. The coefficients obtained during the first cooling between the maximum temperature and $20^{\circ} \mathrm{C}$ should apply for repeated heating and cooling through this temperature range.

The maximum difference between the coefficients of expansion of the samples of tellurium copper and Phosnic bronze is $0.3 \times 10^{-6}$. The coefficients of expansion of these samples are in close agreement with the coefficients of expansion reported by Hidnert [1] for electrolytic copper, nickeliferous copper ( $\mathrm{Ni} 0.35 \%$ ) and arsenical copper (As $0.54 \%$ ).

Nearly all of the coefficients of expansion of the copper-silicon alloy, type B, containing 1.1 percent of zinc and 1.4 percent of silicon, are slightly larger than the coefficients of expansion of tellurium copper.

An examination of the coefficients of expansion of the samples of tellurium nickel brasses and aluminum brass shows that the addition of zine to copper increased ${ }^{3}$ the coefficients of expansion, as was previously shown by Hidnert [1].

The addition of approximately 10 percent of aluminum, 2 percent of iron, and 0.4 percent of tellurium to copper had slight effect on the coefficients of expansion for temperature ranges between $20^{\circ}$ and $300^{\circ} \mathrm{C}$ (see tellurium aluminum bronze). However, an increase of $0.8 \times 10^{-6}$ was noted for the range from $20^{\circ}$ to $400^{\circ} \mathrm{C}$.

The addition of 30 percent of nickel and 0.5 percent of manganese to copper decreased the coefficients of expansion by as much as $1.4 \times 10^{-6}$.

Figure 1 summarizes coefficients of expansion

\footnotetext{
${ }^{3}$ Except for the range from $20^{\circ}$ to $300^{\circ} \mathrm{C}$ on samples 1718 and 1719 during the first heating.
}

of copper-zinc alloys with and without additions of other elements, for the range from room temperature (or $0^{\circ} \mathrm{C}$ ) to $300^{\circ} \mathrm{C}$, from the present and previous investigations $[1,4,5,6,7]$. The curve represents the relation between the coefficients of expansion and the zinc content of the copper-zinc alloys without the addition of other elements in excess of 0.5 percent. This curve shows that the coefficient of expansion increases with increase in the zinc eontent. The broken portion of the curve indicates a change in slope due to a change from the alpha brasses to beta brasses. The addition of 10 to 18 percent of nickel to copper-zinc alloys reduced the coefficients of expansion to a marked extent, but the addition of tin, lead or aluminum increased the coefficients of expansion. The effect of treatment on some alloys is also indicated in figure 1 .

Figure 2 gives a similar summary of the coefficients of expansion of copper-nickel alloys with and without additions of other elements, for several temperature ranges between $-183^{\circ}$ and $+300^{\circ} \mathrm{C}$, from the present and previous investigations $[1$, and 6 to 12 inclusive]. The curves represent the relations between the coefficients of expansion and the nickel content of the copper-nickel alloys without the addition of other elements in excess of 0.5 percent. These curves indicate that the coefficients of expansion decrease with increase in the nickel content. The upper curve was drawn as a broken line, for there are not sufficient data available for the binary alloys. The curvilinear relation between the coefficients of expansion and nickel content (atomic percent) of copper-nickel alloys is typical of relations for properties of binary alloys having structures composed of solid solutions.

Data on the linear thermal expansion of other copper alloys investigated at the National Bureau of Standards have been published in previous papers [1, 7 , and 13 to 17 , inclusive]. 


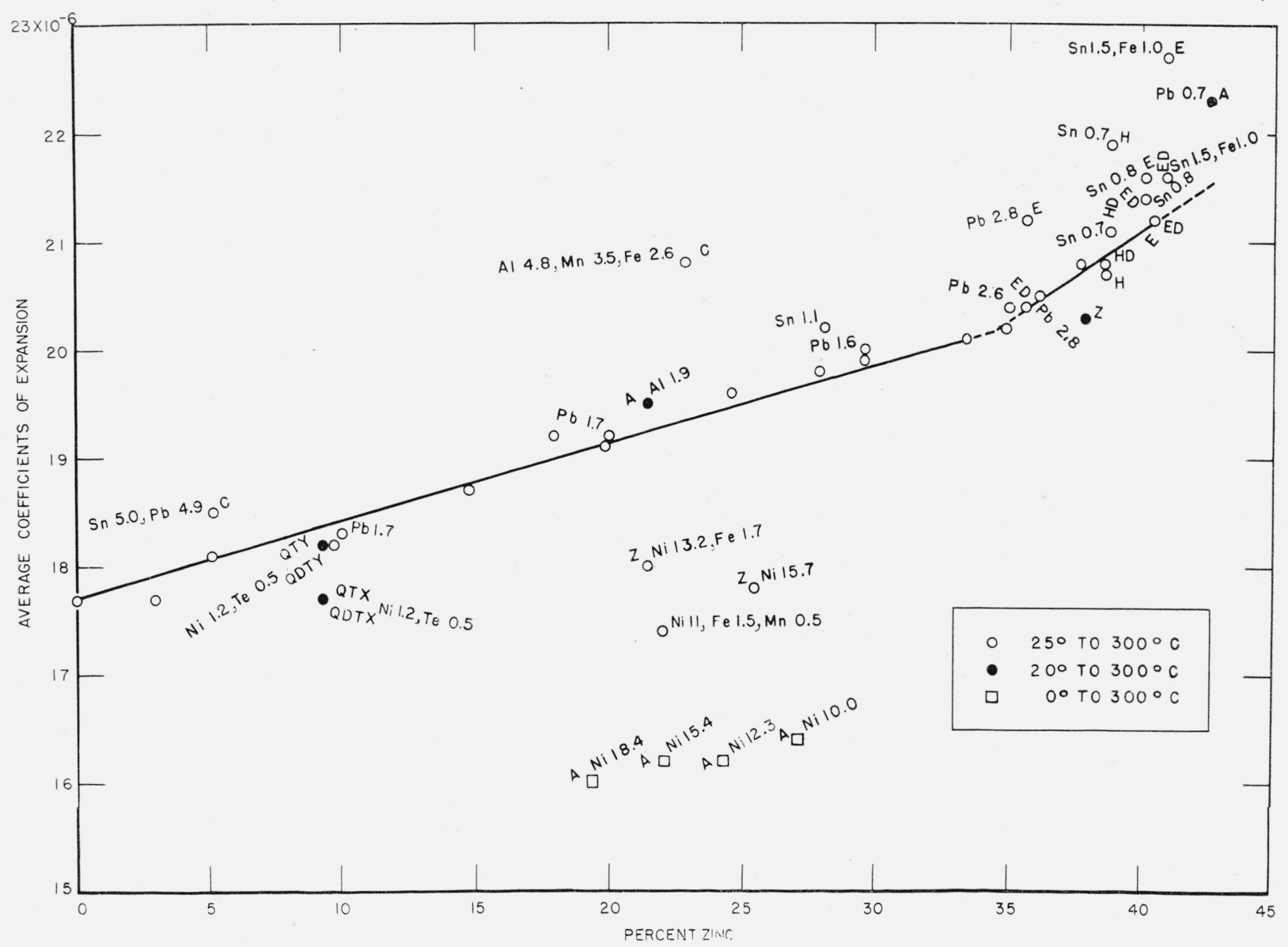

FIGURE 1. Coefficients of linear expansion of copper-zinc alloys with and without additions of other elements.

All plotted points represent values for cold-rolled alloys except those marked with one or more of the following symbols: $A$, Annealed; $C$, cast; $D$, drawn; $E$, extruded; $H$, hot-rolled; $Q$, quenched; $T$, tempered; $X$, aged at room temperature about 18 months; $Y$, aged at room temperature about 40 months; and $Z$, unknown treatment. 


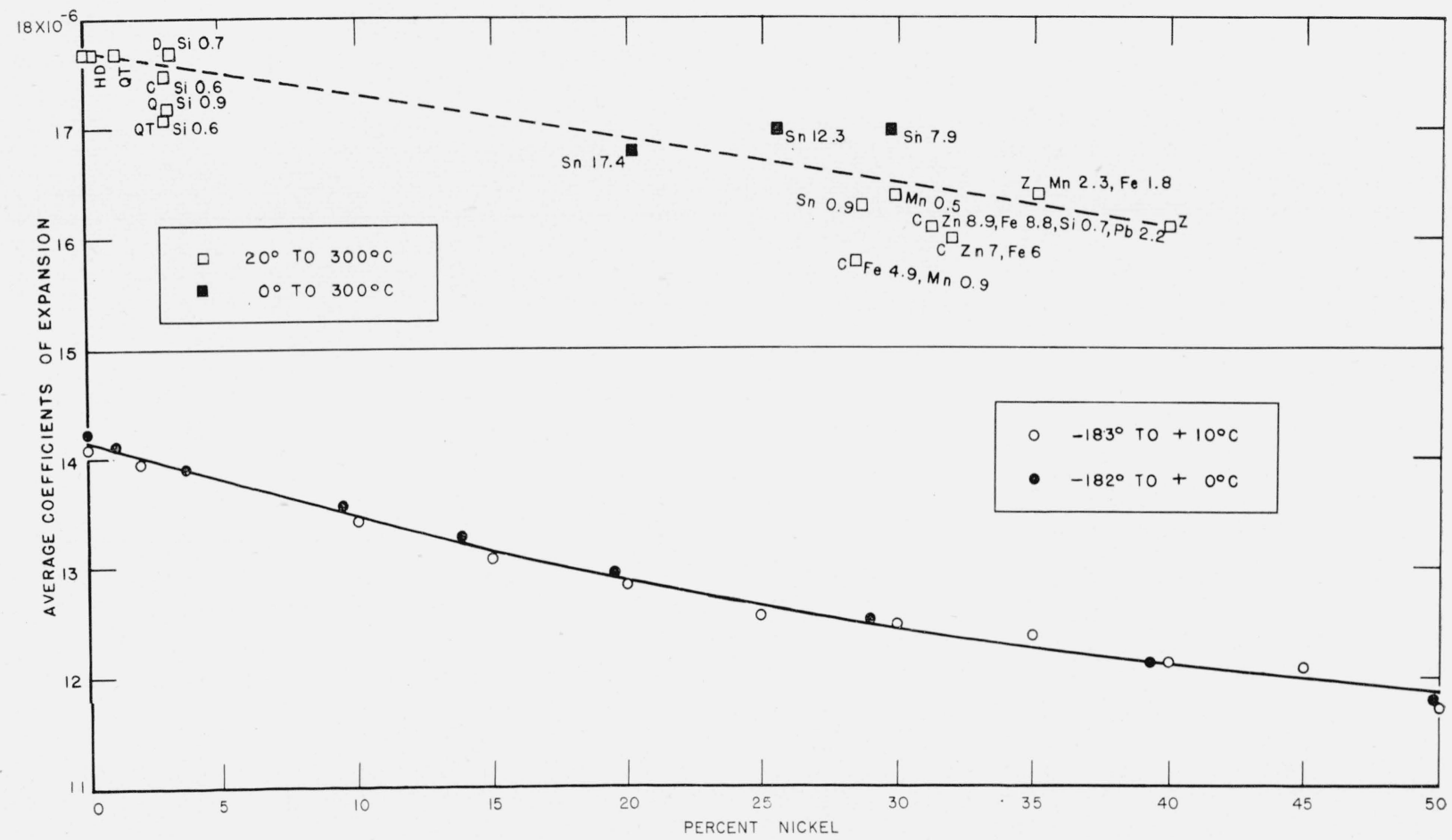

Figure 2. Coefficients of linear expansion of copper-nickel alloys with and without additions of other elements.

All plotted points represent values for annealed alloys except those marked with one or more of the following sym bols: $C$, Cast; $D$, drawn; $E$, extruded; $H$, hot-rolled; $Q$, quenched; $T$, tempered; and $Z$, unknown treatment. 


\section{References}

11] P. Hidnert, BS Sci. Pap. 17, 91 (1922) S410.

[2] H. Esser and H. Eusterbrock, Archiv. Eisenhüttenwesen 14, 341 (1941).

[3] W. Souder and P. Hidnert, BS Sci. Pap. 21, 1 (192627) S524.

[4] Dittenberger and Gehrcke, Z. Instrumentenk. 22, 112 (1902).

[5] H. von Steinwehr and A. Schulze, Z. Metallkunde 26 , 130 (1934).

[6] M. Cook, J. Inst. Metals 58, 151 (1936).

[7] P. Hidnert and G. Dickson, J. Research NBS 31, 77 (1943) RP1550.

[8] L. Holborn and A. Day, Ann. Physik 4, 104 (1901).

[9] Henning, Z. Instrumentenk. 27, 115 (1907).

[10] H. Sieglerschmidt, Mitt. Prüfungsamt 38, 182 (1920).

[11] A. Krupkowski and W. J. De Haas, Communications Phys. Lab. Univ. Leiden 18, No. 194b (1928)
(Translated from Verslag van de Gewone Vergadering der Afdeeling Natuurkunde van de Koninklijke Akademie van Wetenschappen te Amsterdam (27 October 1928), Deel XXXVII, 810-818); or A. Krupkowski, Rv. Mét. (Mémoires) 26, 131, 193 (1929)

[12] S. Aoyama and T. Itô, Sci. Reports Tôhoku Imp. Univ. 27, 348 (1939).

[13] W. P. Price and P. Davidson, Trans. Am. Inst. Metals 10, 133 (1916). See appendix (pp. 151 to 164) for data on thermal expansion by L. W. Schad and P. Hidnert.

[14] P. D. Merica and L. W. Schad, Bul. BS 14, 571 (1919) S321.

[15] P. Hidnert, BS J. Research 12, 391 (1934) RP665.

[16] P. Hidnert, J. Research NBS 16, 529 (1936) RP890.

[17] P. Hidnert, J. Research NBS 30, 75 (1943) RP1518.

Washington, June 9, 1947. 